\title{
Accuracy evaluation of near-surface air temperature from ERA-Interim reanalysis and satellite-based data according to elevation
}

\author{
Jae-Hyun Ryu, Kyung-Soo Han' and Eun-Bin Park \\ Department of Spatial Information Engineering, Pukyong National University
}

\begin{abstract}
In order to spatially interpolate the near-surface temperature $(\mathrm{Ta})$ values, satellite and reanalysis methods were used from previous studies. Accuracy of reanalysis Ta was generally better than that of satellitebased Ta, but spatial resolution of reanalysis Ta was large to use at local scale studies. Our purpose is to evaluate accuracy of reanalysis Ta and satellite-based Ta according to elevation from April 2011 to March 2012 in Northeast Asia that includes various topographic features. In this study, we used reanalysis data that is ERAInterim produced by European Centre for Medium-Range Weather Forecasts (ECMWF), and estimated satellite-based Ta using Digital Elevation Meter (DEM), Normalized Difference Vegetation Index (NDVI), difference between brightness temperature of $11 \mu \mathrm{m}$ and $12 \mu \mathrm{m}$, and Land Surface Temperature (LST) data. The DEM data was used as auxiliary data, and observed Ta at 470 meteorological stations was used in order to evaluate accuracy. We confirmed that the accuracy of satellite-based Ta was less accurate than that of ERAInterim Ta for total data. Results of analyzing according to elevation that was divided nine cases, ERA-Interim Ta showed higher accurate than satellite-based Ta at the low elevation (less than $500 \mathrm{~m}$ ). However, satellitebased Ta was more accurate than ERA-Interim Ta at the higher elevation from 500 to $3500 \mathrm{~m}$. Also, the width of the upper and lower quartile appeared largely from 2500 to $3500 \mathrm{~m}$. It is clear from these results that ERAInterim Ta do not consider elevation because of large spatial resolution. Therefore, satellite-based Ta was more effective than ERA-Interim Ta in the regions that is range from $500 \mathrm{~m}$ to $3500 \mathrm{~m}$, and satellite-based Ta was recommended at a region of above $2500 \mathrm{~m}$.
\end{abstract}

Key Words : near-surface air temperature, ERA-Interim, elevation

\section{Introduction}

The near-surface air temperature $(\mathrm{Ta})$, that was defined as temperature of $2 \mathrm{~m}$ above from the ground of meteorological stations, is one of useful variables in various research fields such as meteorology, climatology, and hydrology (e.g. Wenbin et al., 2013). $\mathrm{Ta}$ is conventionally observed at meteorological stations with high accuracy (Stisen et al., 2007), but these point data cannot consider variation by space

Received October 18, 2013; Revised November 8, 2013; Accepted November 20, 2013.

$†$ Corresponding Author: Kyung-Soo Han (kyung-soo.han@pknu.ac.kr)

This is an Open-Access article distributed under the terms of the Creative Commons Attribution Non-Commercial License (http://creativecommons. org/licenses/by-nc/3.0) which permits unrestricted non-commercial use, distribution, and reproduction in any medium, provided the original work is properly cited 
(Prihodko and Goward, 1997; Wenbin et al., 2013). A lot of studies about spatial interpolation for Ta have been attempted. Reanalysis and satellite are representative methods in order to spatially interpolate Ta values. Reanalysis Ta data, such as ERA-Interim of European Centre for Medium-Range Weather Forecasts (ECMWF), Climatic Research Unit (CRU), and National Centers for Environmental Prediction/ National Center for Atmospheric Research (NCEP/ NCAR), have been produced. In the previous studies, satellite-based Ta was estimated through empirical and physical method (Prihodko and Goward, 1997; Cresswell et al., 1999; Stisen et al., 2007; Yan et al., 2009; Wenbin et al., 2013). Satellite-based Ta has commonly lower accuracy than reanalysis Ta data. However, reanalysis Ta data have high bias from complex topography and high local elevation (Zhao et al., 2008). Relatively large spatial resolution of reanalysis data can be caused high error values, because Ta is affected by topography (e.g. elevation). In the previous studies, relation of Ta and elevation was analyzed. Ta decreases approximately from $0.55^{\circ} \mathrm{C}$ to $0.60{ }^{\circ} \mathrm{C}$ per $100 \mathrm{~m}$ of elevation change (Rolland, 2003; Frauenfeld et al., 2005). You et al. (2010) showed that relationship of elevation, Ta trend magnitude, and mean Ta. Han et al. (2005) estimated Ta considering Digital Elevation Meter (DEM) that is related to the moist adiabatic lapse rate.

Our main objective in this study are to perform accuracy evaluation of analysis Ta and satellite-based Ta data according to variance of elevation. We analyzed data quality of analysis Ta and satellite-based Ta data in order to evaluate accuracy according to elevation, and presented optimal elevation threshold of Ta data for reanalysis Ta and satellite-based Ta data.

\section{Data \& Method}

The study area was set to the Northeast Asia region

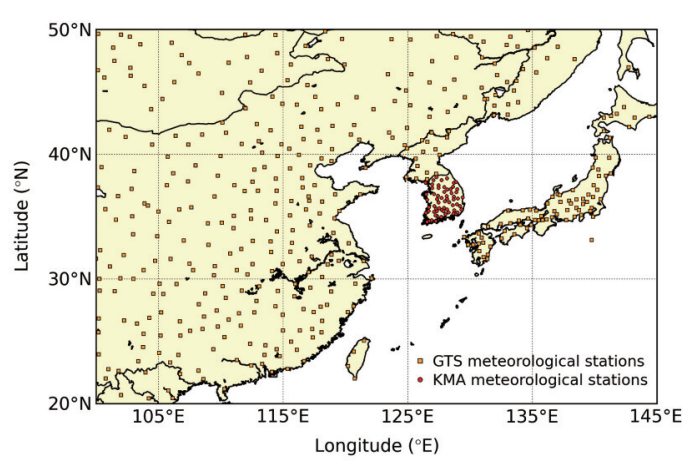

Fig. 1. Study region in Northeast Asia. The squares mean GTS meteorological stations, and the circles mean KMA meteorological stations.

(Fig. 1). This region included the Taebaek mountains in the Korean Peninsula, Nushan mountains, Taihang mountains in the China, and Kiso mountains in Japan. Observed Ta data from the 64 Korea Meteorological Administration (KMA) and the 406 Global Telecommunication System (GTS) were used to evaluate accuracy of reanalysis Ta and satellite Ta. Data of midday and 15:00 local time were used in order to match with satellite-based Ta data and reanalysis Ta data from April 2011 to March 2012. The satellitebased Ta was estimated using the Communication, Ocean and Meteorological Satellite (COMS) satellite and the Systeme Pour l'Observation de la (SPOT) satellite data. The methodology was considered moisture conditions of surface and atmosphere, and was applied for weighting function for estimating satellite-based Ta (Kim and Han, 2013). This satellitebased algorithm estimated midday Ta, and spatial resolution of satellite-based Ta is $1 \mathrm{~km}$. ERA-Interim reanalysis data at 15:00 local time was used instead of NCEP/NCAR, because NCEP is less reliable than ERA-40 which is previous versions of ERA-Interim (You et al., 2010). The ERA-Interim reanalysis nearsurface air temperature (ERA-Interim Ta) data was provided every 6 hours based on UTC. The ERAInterim Ta was calculated using a bilinear interpolation method (Simmons et al., 2004), and spatial resolution of ERA-Interim Ta data is 0.75 degree. To determine 
Table 1. Coefficient of variables for each case

\begin{tabular}{c|c|c|c|c|c}
\hline \hline Case & DEM $(\mathrm{m})$ & NDVI & BT $_{11}-\mathrm{BT}_{12}(\mathrm{~K})$ & LST $(\mathrm{K})$ & Constant \\
\hline Case1 & -0.0011 & 4.9763 & -0.7875 & 0.5719 & 117.3479 \\
\hline Case2 & -0.0025 & 3.2825 & 0.7681 & 0.3920 & 172.9966 \\
\hline Case3 & -0.0025 & 4.8849 & 1.2763 & 0.2737 & 208.7916 \\
\hline Case4 & -0.0014 & 9.2404 & 1.1254 & 0.5789 & 110.6279 \\
\hline Case5 & -0.0012 & 6.8664 & 1.1219 & 0.5761 & 114.4150 \\
\hline Case6 & -0.0017 & 8.4821 & 1.4664 & 0.5492 & 122.1014 \\
\hline Case7 & -0.0015 & 12.7825 & -2.2061 & 0.8099 & 44.2788 \\
\hline Case8 & -0.0011 & 10.9248 & -2.8375 & 0.8848 & 25.2093 \\
\hline Case9 & -0.0012 & 10.9466 & -3.7676 & 0.9306 & 12.8726 \\
\hline \hline
\end{tabular}

elevation, DEM from United States Geological Survey (USGS) was used in Northeast Asia. In this study, USGS 30 ARC-second global elevation data (GTOPO30) was used as auxiliary data. GTOPO30 was retrieved from eight sources of elevation information that consist of raster and vector data (Harding et al., 1999).

Satellite-based Ta was estimated as following equation 1:

$$
\begin{aligned}
T a_{k}= & a_{k} \cdot D E M+b_{k} \cdot N D V I+c_{k} \cdot\left(B T_{11}-B T_{12}\right) \\
& +d_{k} \cdot L S T+e_{k}
\end{aligned}
$$

where unit of $D E M$ is $\mathrm{m}$, and Normalized Difference Vegetation Index (NDVI) is vegetation index. $B T_{11}$ and $B T_{12}$ means brightness temperature of $11 \mu \mathrm{m}$ and $12 \mu \mathrm{m}$ from COMS satellite, unit of those is degrees Kelvin (K), and unit of $L S T$ is degrees Kelvin (K). Table 1 showed coefficients for variables. According to elevation data, we were divided into nine cases to evaluate effects of elevation for ERA-Interim and satellite Ta. The elevation was separated as follows: 0 $\sim 500 \mathrm{~m}, 500 \sim 1000 \mathrm{~m}, 1000 \sim 1500 \mathrm{~m}, 1500 \sim 2000$ $\mathrm{m}, 2000 \sim 2500 \mathrm{~m}, 2500 \sim 3000 \mathrm{~m}, 3000 \sim 3500 \mathrm{~m}$, $3500 \sim 4000 \mathrm{~m}$, and more than $4000 \mathrm{~m}$.

\section{Results}

Standard Deviation (SD) of elevation was computed based on spatial resolution of ERA data. SD of

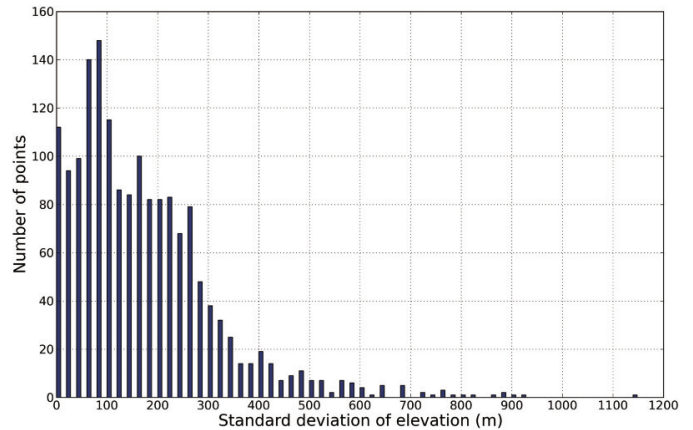

Fig. 2. Standard deviation distribution of elevation based on spatial resolution of ERA data.

elevation was distributed within $300 \mathrm{~m}$ in general (Fig. 2). Mean value of SD was $177.97 \mathrm{~m}$, and median value of SD was $149.58 \mathrm{~m}$ in Northeast Asia. We estimated satellite-based midday Ta using various variables, and evaluated accuracy of ERA-Interim Ta and satellitebased Ta. The validation results of the accuracy for ERA-Interim $\mathrm{Ta}$ and satellite-based $\mathrm{Ta}$ using meteorological station data were shown in Fig. 3. The determinant coefficient for between observed $\mathrm{Ta}$ and ERA-Interim Ta was 0.9582, and determinant coefficient for between observed Ta and satellite-based Ta was 0.9289 . The RMSE was $2.6315 \mathrm{~K}$, and bias was -1.1048 K from ERA-Interim Ta (Fig. 3a), and the RMSE was $3.2279 \mathrm{~K}$, and bias was $0.1575 \mathrm{~K}$ from satellite-based Ta (Fig. 3b). The slope of ERA-Interim Ta was close to 1 than the slope of satellite-based Ta, and the intercept of ERA-Interim Ta was close to 0 than the intercept of satellite-based Ta. 

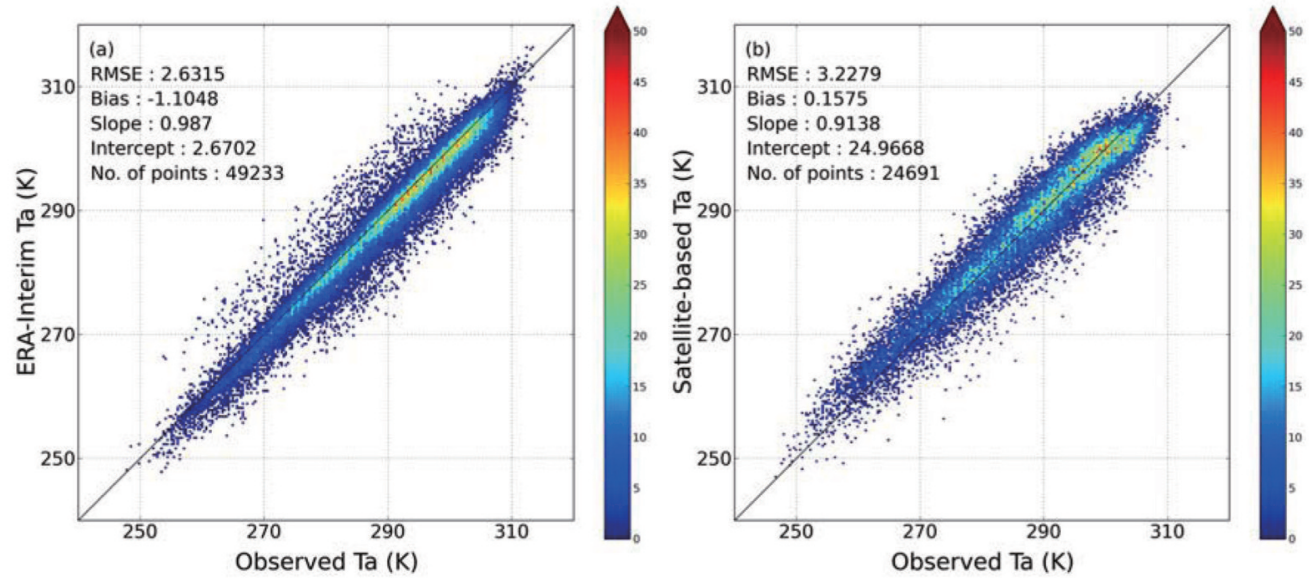

Fig. 3. (a) scatter plot about correlation between observed Ta and ERA-Interim Ta, (b) scatter plot about correlation between observed $\mathrm{Ta}$ and satellite-based Ta.

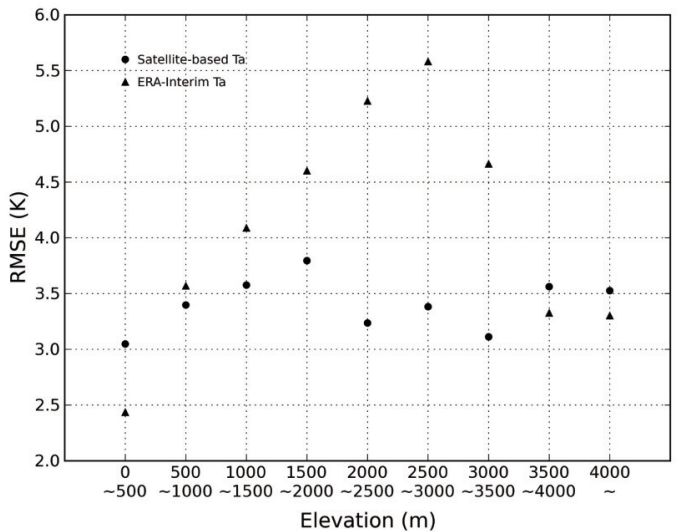

Fig. 4. RMSE of ERA-Interim Ta and satellite-based Ta according to elevation.

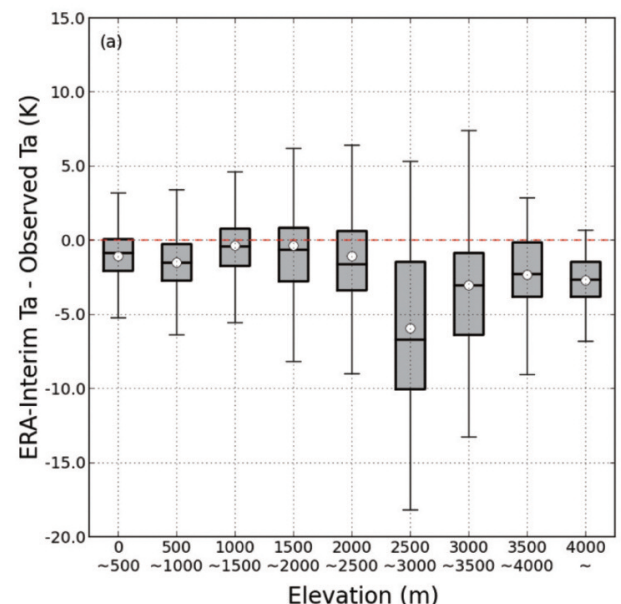

The distribution for accuracy of classified Ta data depending on elevation was shown in Fig. 4. Low elevation from 0 to $500 \mathrm{~m}$ represented that ERAInterim Ta was better than satellite-based Ta. However, elevation from 500 to $3500 \mathrm{~m}$ represented that satellitebased Ta was better than ERA-Interim Ta. ERAInterim $\mathrm{Ta}$ and satellite-based $\mathrm{Ta}$ were analyzed depending on elevation (Fig. 5). ERA-Interim Ta had box plot of irregular size from more than $2500 \mathrm{~m}$ (Fig. 5a). The upper and lower quartile, and the minimum values of ERA-Interim Ta were better than that of satellite-based Ta within less than $2000 \mathrm{~m}$, but median

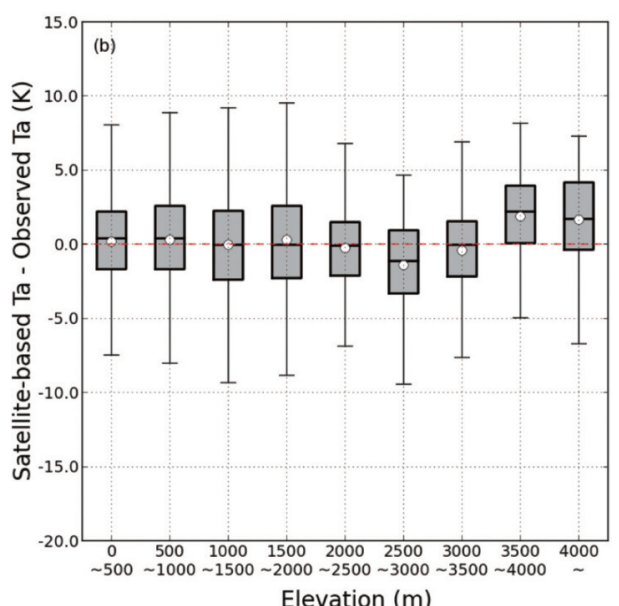

Fig. 5. (a) box plot of difference between observed Ta and ERA-Interim Ta depending to elevation, (b) box plot of difference between observed Ta and satellite-based Ta according to elevation. 
values were largely located apart the zero point from more than 2500 m as follows: $2500 \sim 3000 \mathrm{~m}$ : -6.7212 $\mathrm{K}, 3000 \sim 3500 \mathrm{~m}:-3.0674 \mathrm{~K}, 3500 \sim 4000 \mathrm{~m}:-$ $2.2709 \mathrm{~K}$, and more than $4000 \mathrm{~m}:-2.6420 \mathrm{~K}$. The width of the upper and ERA-Interim quartile from 2500 to $3500 \mathrm{~m}$ was coarse. On the other hand, satellitebased Ta had box plot of constant range in all cases respectively (Fig. 5b). The maximum and minimum values for difference between observed Ta and satellitebased Ta were located from -10 to $10 \mathrm{~K}$. Although median and mean values were located a little away from the zero point over $2500 \mathrm{~m}$, the median values were a little as follows: $2500 \sim 3000 \mathrm{~m}:-1.1189 \mathrm{~K}$, $3000 \sim 3500 \mathrm{~m}:-0.0625 \mathrm{~K}, 3500 \sim 4000 \mathrm{~m}: 2.2047$ $\mathrm{K}$, and more than $4000 \mathrm{~m}: 1.7150 \mathrm{~K}$.

\section{Discussion}

Accuracy of satellite-based $\mathrm{Ta}$ and reanalysis $\mathrm{Ta}$ were evaluated according to elevation in Northeast Asia. RMSE, Bias, and intercept value of ERA-Interim data were better than that of satellite-based data. These results mean that the accuracy of ERA-Interim Ta was higher than the accuracy of satellite-based Ta, and the ERA-Interim Ta tends to underestimate trends of the ground truth like previous studies (Fauenfeld $e t$ al., 2005; You et al., 2010). However, the accuracy of ERA-Interim Ta and satellite-based Ta was different depending on the elevation. Error of ERA-Interim Ta was higher than that of satellite-based Ta from 500 $3500 \mathrm{~m}$. This result indicates that ERA-Interim Ta does not take higher elevation into account, because large spatial resolution of ERA-Interim data is large. When considering elevation of the study area, satellite-based Ta was better than ERA-Interim Ta from $56.12 \%$ of study area. Colombi et al. (2007) reported that satellitebased Ta was better than the Inverse Distance Weighting (IDW) interpolation method from region of high elevation (more than $2000 \mathrm{~m}$ ). Therefore, satellite- based Ta is more effective than ERA-Interim Ta at the region that is range from 500 to $3500 \mathrm{~m}$, and the threshold of elevation for ERA-Interim Ta was established at the region of above $2500 \mathrm{~m}$ in the Northeast Asia. Further study is required to evaluate accuracy of satellite-based Ta and reanalysis data considering various climate factors such as wind speed, humidity.

\section{Acknowledgment}

This work was funded by the Korea Meteorological Administration Research and Development Program under Grant CATER 2012-2066.

\section{References}

Colombi, A., C.D. Michele, M. Pepe, and A. Rampini, 2007. Estimation of daily mean air temperature from MODIS LST in Alpine areas, EARSeL eProceedings, 6: 38-46.

Cresswell, M.P., A.P. Morse, M.C. Thomson, and S.J. Connor, 1999. Estimating surface air temperature, from Meteosat land surface temperatures, using an empirical solar zenith angle model, International Journal of Remote Sensing, 20: 1125-1132.

Frauenfeld, O.W., T. Zhang, and M.C. Serreze, 2005. Climate change and variability using European Centre for Medium-Range Weather Forecasts reanalysis (ERA-40) temperatures on the Tibetan Plateau, Journal of Geophysical Research, 110: D02101.

Han, K.S., A.A. Viau, Y.S. Kim, and J.L. Roujean, 2005. Statistical estimate of the hourly nearsurface air humidity in eastern Canada in merging NOAA/AVHRR and GOES/IMAGER observations, International Journal of Remote 
Sensing, 26: 4763-4784.

Harding, D.J., D.B. Gesch, C.C. Carabajal, and S.B. Luthcke, 1999. Application of the shuttle laser altimeter in an accuracy assessment of GTOPO30, a global 1-kilometer digital elevation model, International Archives of Photogrammetry and Remote Sensing, 32: 8185.

Kim, D.Y., and K.S. Han, 2012. Remotely sensed retrieval of midday air temperature considering atmospheric and surface moisture conditions, International Journal of Remote Sensing, 34: 247-263.

Prihodko, L., and S.N. Goward, 1997. Estimation of air temperature from remotely sensed surface observations, Remote Sensing of Environment, 60: 335-346.

Rolland, C., 2003. Spatial and seasonal variations of air temperature lapse rates in Alpine regions, Journal of Climate, 16: 1032-1046.

Simmons, A.J., P.D. Jones, V. da Costa Bechtold, A.C.M. Beljaars, P.W. Kallberg, S. Saarinen, S.M. Uppala, P. Viterbo, and N. Wedi, 2004. Comparison of trends and low-frequency variability in CRU, ERA-40, and NCEP/ NCAR analyses of surface air temperature, Journal of Geophysical Research: Atmospheres (1984-2012), 109: D24115.
Stisen, S., I. Sandholt, A. Nørgaard, R. Fensholt, and L. Eklundh, 2007. Estimation of diurnal air temperature using MSG SEVIRI data in West Africa, Remote Sensing of Environment, 110: 262-274.

Wenbin, Z., L. Aifeng, J. Shaofeng, 2013. Estimation of daily maximum and minimum air temperature using MODIS land surface temperature products, Remote Sensing of Environment, 130: 62-73

Yan, H., J. Zhang, Y. Hou, and Y. He, 2009. Estimation of air temperature from MODIS data in east China, International Journal of Remote Sensing, 30: 6261-6275.

You, Q., S. Kang, N. Pepin, W.A. Flugel, Y. Yan, H. Behrawan, and J. Huang, 2010. Relationship between temperature trend magnitude, elevation and mean temperature in the Tibetan Plateau from homogenized surface stations and reanalysis data, Global and Planetary Change, 71: 124-133.

Zhao, T., W. Guo, and C. Fu, 2008. Calibrating and evaluating reanalysis surface temperature error by topographic correction, Journal of Climate, 21: 1440-1446. 